\title{
Awards and Citations
}

\section{Response by Shanan E. Peters for the presentation of the 2014 Charles Schuchert Award of the Paleontological Society}

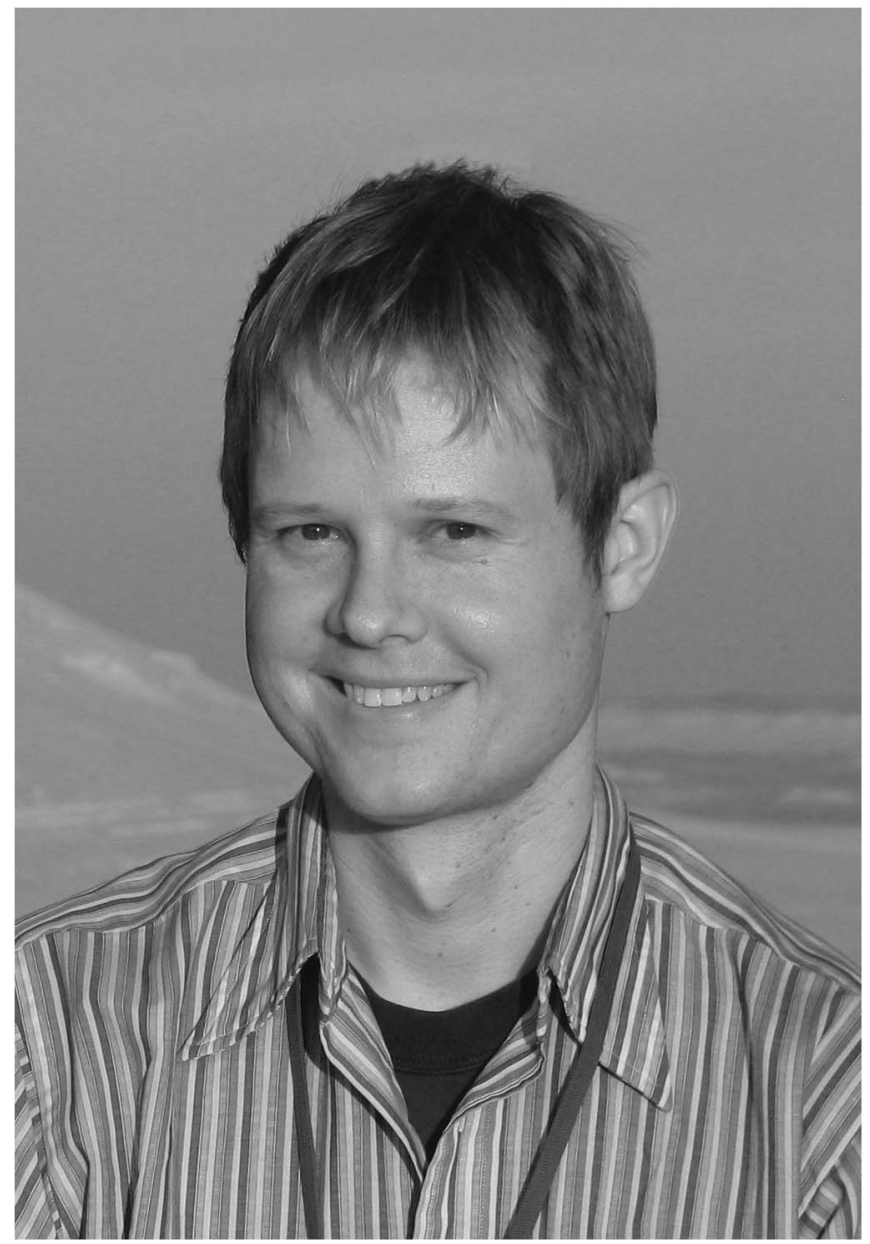

Shanan E. Peters

Thank you Michael, for your kind words, and thank you to the Paleontological Society for this recognition. It is a humbling privilege to have my name appended to such a distinguished list of previous awardees. It is also thrilling that this award bears the name of the remarkable Ohio-born paleontologist, Charles Schuchert, who began his pursuit of paleontology in much the same way that this Ohio boy did-plucking fossils from the gray slopes of the Cincinnatian.

Some eleven years ago, in his acceptance speech for this same award, Steven Holland acknowledged the Paleobiology Database and the vision of John Alroy and Charles Marshall in creating it. Steve predicted then that beyond the analysis of Phanerozoic diversity, the Paleobiology Database would become an integral part of our field programs because it would "ensure that we build upon the data of the generations that have come before us and that our data are preserved for the generations that follow." Eleven years later that potential is still there.

Fundamentally, we all depend on field- and specimen-based data. Such data are hard earned and complex, and their acquisition, with few exceptions, requires great skill, not a little luck, and, most importantly, time. So much so that many important questions cannot possibly be addressed in a field campaign of one's own; instead field- and specimen-based data must be mined from the literature and museums and then synthesized into a framework conducive to quantitative analysis. This too is hard work requiring skills of a different sort and, most importantly, time. I share Steve's vision for a time when we can more fully harness the collective body of knowledge that has been generated 
on the rock and fossil records, and then either stay in, or return to, the field and museum collections to produce new and better data that builds higher and faster, as well as broader, the edifice of our discipline's knowledge. A common data infrastructure is essential to both the effective communication of our science and to facilitating the integration of biological and geological datasets that are essential to formulating and testing the next generation of hypotheses in paleobiology.

There are so many people I'd like to thank, but it is impossible to list them all. I want to first thank my parents and my siblings for their love and support, beyond measure. I want to thank my uncle, Ken Karns, for conveying to me as a boy the passion for fossil collecting and for his many years of companionship in the field. My grandmother Sally Karns instilled in my uncle his love of fossils; for this and so much more am I grateful. I also want to thank the late David Thrush, high school science teacher in one of the poorer districts in Ohio, for buying me that invertebrate zoology textbook, and for taking time on a weekend to go fossil hunting. Sonny Baxter, you taught me much, and at just the right time. I am also grateful to my mentors at Denison University, Kennard Bork in particular, but also Todd Frolking, Bob Malcuit, and Chuck Bailey; you took this fossil collector and rounded him out as a scholar. I would also like to thank the entire set of instructors and graduate students at the University of Chicago who, during my first year in residence, truly made me feel like I was in way over my head. That was exactly what I needed. My time at Michigan was invaluable, and I thank the Fellows, Philip Gingerich, and the Museum of Paleontology and sedimentary geology faculty there. Bruce Wilkinson-thanks for those charts. I'm also grateful for the many close friends that I have made in our field; F.O.P., I hope you know what you mean to me.

There are two more people I would like to acknowledge. Jack Sepkoski passed soon after I arrived at Chicago, and Michael Foote stepped in as my advisor. Although I regret Jack's early passing for many reasons, I could not have found a better complement in a mentor. I felt at home and confident in the field, but lost and incompetent quantitatively and in front of a computer terminal. When I asked Michael to help improve my skills in these areas, he agreed. Each week I would get an email from him with one question, the solution to which required writing a program. At first I wouldn't even understand the question, let alone how to even begin to program the answer. But, each week I tried, and learned from my fellow graduate students, and tried again. It was the most exciting period of intellectual growth I've ever experienced. Thank you for that, Michael, and for all the late nights over Scotch. I look forward to many more.

Madame President, members of Council, and members of the Paleontological Society, please accept my gratitude for this award. Thank you.

Department of Geoscience University of Wisconsin, Madison Madison, Wisconsin 53706 peters@geology.wisc.edu 